\title{
Configuração de arranjos interorganizacionais e implementação de programas públicos
}

\author{
Sheila Cristina Tolentino Barbosa * \\ Janann Joslin Medeiros **
}

\begin{abstract}
Resumo
A implementação de programas públicos através de relações interorganizacionais envolvendo vários níveis de governo e uma variedade de instituições públicas e privadas é uma tarefa complexa. 0 desafio é estabelecer de um formato que seja capaz de induzir a ação para 0 alcance dos resultados planejados. No exame dessa questão, o presente trabalho focaliza o Programa de Alfabetização e Capacitação de Jovens e Adultos de 1998, coordenado pela Superintendência de Desenvolvimento do Nordeste. Utilizando uma metodologia qualitativa para a coleta e análise de dados, o estudo investigou a configuração do arranjo interorganizacional do referido programa. Observou-se que o arranjo adquiriu uma configuração hierárquica, bastante verticalizada, centralizada e pouco interativa tendo como principal conseqüência a inadequação do formato do arranjo para o objetivo proposto. Conclui-se o trabalho tecendo recomendações para a construção de redes interorganizacionais adequadas aos objetivos das ações propostas.
\end{abstract}

Palavras-chave: Implementação; Arranjos Interorganizacionais; Programas Públicos.

\begin{abstract}
The implementation of public programs is a complex task, often involving interorganizational relations at several levels of government and among a variety of public and private institutions. The challenge is to establish a format for these relationships that permits achievement of intended results. This paper examines the interorganizational arrangements established for the 1998 Program for Literacy and Training of Young People and Adults coordinated by the Superintendency for Developoment of the Northeast of Brazil (SUDENE). This study, employing qualitative methods for the collection and analysis of data, found that the configuration of the interorganizational relations for the implementation of that Program took the form of an hierarchical, centralized, organizational set with little or no interaction among most of the elements. This format was seen to be inadequate for achievement of the objectives of the Program. Recommendations are made with respect to configuration of interorganizational networks for public programimplementation appropriate to the achievement of intended results.
\end{abstract}

Keywords: Implementation; Interorganizational Arrangements; Public Program

\section{Introdução}

O envolvimento de um maior número de atores na implementação de programas resultante da descentralização da ação estatal tem, na mesma proporção, revelado novos obstáculos à gestão dos programas públicos oriundos das políticas públicas federais. $\mathrm{O}$ atual desenho dessas políticas propõe sua implantação através de redes de implementadores (UNICAMP/NEPP, 2000) gerenciados por uma estrutura institucional capaz de mobilizar, articular e monitorar tais atores. Consequientemente, são estabelecidas diversas relações interorganizacionais entre o governo e as organizações envolvidas na implementação de programas públicos, implicando a necessidade de mecanismos de coordenação interorganizacional efetivos.

\footnotetext{
* Faculdades Santo Agostinho. E-mail: sheila@ santoagostinho.edu.br.

** Unviersidade Nacional de Brasília. E-mail: janann@ unb.br.

Artigo recebido em julho de 2004 e aceito em setembro de 2004.
} 
Embora boa parte dos estudos recentes sobre relações interorganizacionais destaquem as relações de interdependência no contexto de mercado (GRANDORI e SODA, 1995; HALL, 1996, MILES e SNOW, 1994), tem sido comum a formação de redes interorganizacionais no contexto da administração pública, especificamente na prestação de serviços sociais (LEVINE, S. e WHITE, P. E, 1961).

Para a observação de aspectos do estabelecimento de arranjos interorganizacionais na gestão pública, é apresentado a seguir um estudo de caso sobre a implementação do Programa de Alfabetização e Capacitação de Jovens e Adultos, implementado em 1998 pela Sudene, dentro de um programa de ações integradas para o combate aos efeitos da seca, com a participação de governos estaduais, através de um grande arranjo interorganizacional, seguindo a nova tendência de descentralização da ação estatal.

Este artigo foi estruturado a partir do referencial teórico que adota conceitos sobre relações interorganizacionais, e a metodologia utilizada para o desenvolvimento da pesquisa foi o estudo de caso estruturado previamente, envolvendo um conjunto de códigos que relaciona os conceitos do referencial teórico com as evidências.

O estudo das relações interorganizacionais foi focalizado no âmbito das relações entre a Sudene e governos estaduais com seus respectivos órgãos executores, não se estendendo à análise das ligações entre estes últimos e os implementadores no nível local que formam uma rede tanto mais extensa e complexa. Contudo, espera-se que as análises e conclusões pertinentes a esse primeiro nível do arranjo interorganizacional, em uma generalização analítica (YIN,1994), possam ser utilizadas em níveis sucessivos das relações interorganizacionais da implementação.

Finalmente é apresentada a conclusão, com uma síntese da configuração do arranjo interorganizacional estabelecido para a implementação do programa de Alfabetização e Capacitação de 1998.

\section{Marco conceitual}

\section{Configuração de arranjos interorganizacionais}

Para estabelecer uma análise sobre a coordenação em redes interorganizacionais, visando a implementação de programas públicos, é necessário, antes de tudo, expor um conceito de relações interorganizacionais e examinar a tipologia dessas relações, cujas características vão delinear particularidades relevantes ao processo de análise dos aspectos de coordenação envolvidos nessas mesmas relações.

Esforços nesse sentido têm sido feitos por diversos autores; no entanto, uma referência teórica que serve de base para vários estudos é aquela proposta por Van De Ven e Walker (1979), cujo conceito estabelece que a relação interorganizacional ocorre quando duas ou mais organizações executam transações de recursos de qualquer tipo, sejam financeiros, materiais, clientes e serviços técnicos.

Quanto às configurações dos arranjos de relações interorganizacionais, Van De Ven e Walker (1979) estabelecem três tipos a saber (ver figura 1):

- a relação aos pares - duas organizações estabelecem relações de mão dupla, sendo esse o mais simples dos arranjos das relações interorganizacionais;

- o conjunto interorganizacional - um conjunto de organizações se forma pela relação de par estabelecida entre uma organização focal e as diversas outras organizações membros, sem que estas mantenham ligações entre si. Tal configuração é denominada por Grandori (1997) "constelação", enfatizando a importância da liderança de uma agência central para coordenar as competências críticas e as incertezas;

- a rede interorganizacional - diversas organizações estabelecem relações diretas entre si. As ligações são permitidas em todas as direções, gerando um maior volume de interações com maior grau de complexidade, proporcionando maior riqueza de experiências e, em contrapartida, exigindo mais dos mecanismos de 
coordenação e controle, sobretudo, dos sistemas de informação, visando a uma interação com resultados satisfatórios.

\section{Figura 1}

\section{Formatos de arranjos interorganizacionais}

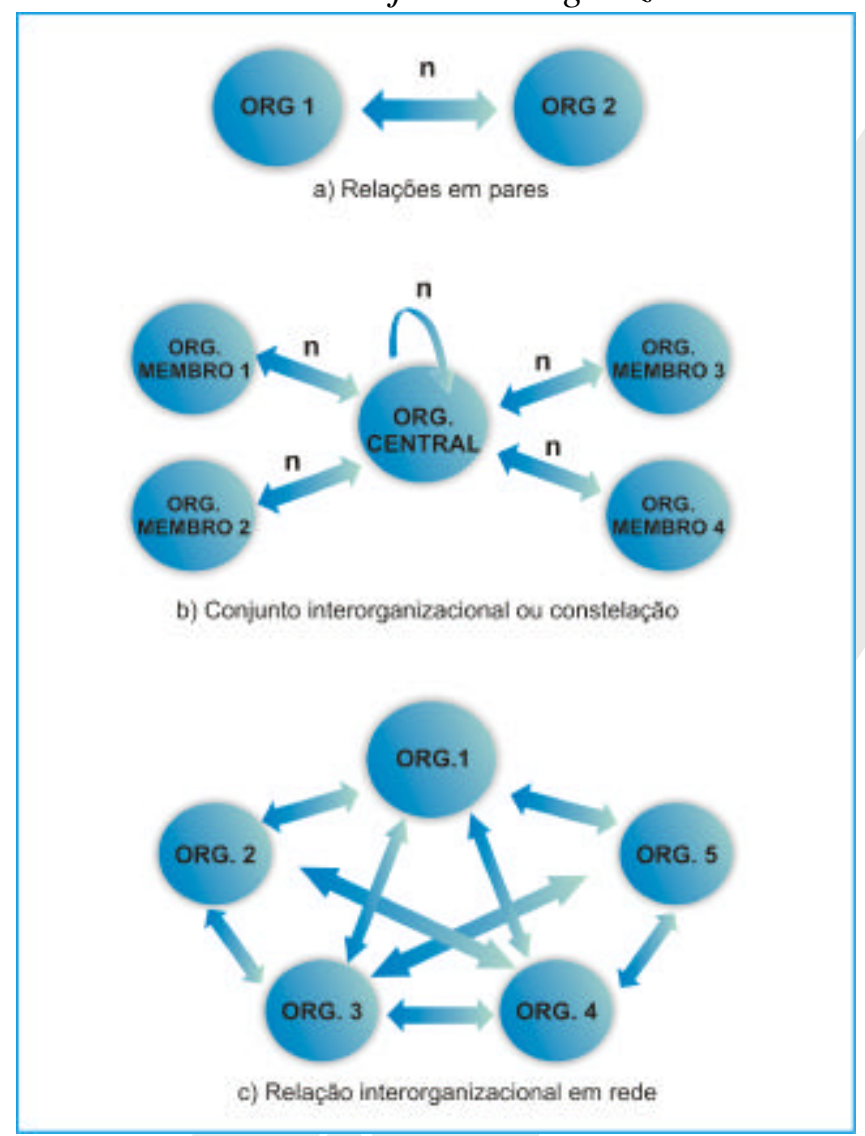

Fonte: Van DeVen e Walker (1979).

O conjunto e a rede interorganizacional podem também ser vistos como uma série de relações de pares, cujas características - dependência de recursos, frequiência de comunicação, consciência e consenso - podem quantificar as relações em termos de direção, grau ou quantidade.

Os estudos sobre o conjunto interorganizacional, geralmente, se limitam a medir e comparar as séries de relações entre a agência central e as agências membros do conjunto, o que pode ajudar na compreensão de como a agência central afeta ou é afetada pelas agências membros (VAN DE VEM e WALKER, 1979; GRANDORI, 1997).

De outra perspectiva, a tipologia das redes estabelecidas através das relações interorganizacionais está relacionada às formas de coordenação utilizadas, que separam tais redes nos seguintes tipos (MILES e SNOW, 1994):

- rede estável - a coordenação da relação interorganizacional é especializada e central, com desenvolvimento de atividades em integração vertical;

- rede dinâmica - delineada por alianças temporárias, sob coordenação central, onde existe uma combinação da avaliação central com uma autonomia local de organizações responsáveis pela produção de bens ou serviços, com integração horizontal;

- rede interna - definida por relações que estabelecem um mercado interno de troca de bens e serviços entre organizações que compõem uma organização central, ou melhor dizendo, entre estruturas de uma 
determinada organização, com a utilização dos recursos humanos e materiais dessas estruturas no desenvolvimento de determinadas atividades. (nesse caso, especificamente, nas atividades de coordenação).

Outra diferenciação de tipologias de redes interorganizacionais é proposta por Grandori e Soda (1995), tendo como base o grau de formalização, assimetria ou descentralização e um mix de mecanismos de coordenação. A referida diferenciação é composta por três tipos de rede, caracterizadas da seguinte forma:

- redes sociais - são redes não formalizadas, dedicadas apenas à troca de bens sociais, tais como prestígio, status, amizade e oportunidades de carreira. Esse tipo de rede é observada nas relações pessoais ou entre empreendedores ou gerentes, para troca de informações confidenciais de valor econômico potencial.

- redes burocráticas - são redes formalizadas por acordos ou contratos de troca ou associação. Contudo, o grau de formalização é variável e não supre a necessidade das relações presentes nas redes sociais. Podem ser centralizadas como as associações, federações e consórcios, ou descentralizadas como as redes de franquias;

- redes proprietárias - são formalizadas e utilizam o direito de propriedade como sistema de incentivo à cooperação, podendo ser centralizadas, como as joint venture, ou não centralizadas, como as capital venture.

\section{Bases metodológicas}

A estratégia adotada para o desenvolvimento da pesquisa foi o estudo de caso. Segundo (YIN,1994), essa é a estratégia mais usual nas pesquisas de campo das ciências sociais, sendo a mais indicada para pesquisas que se orientam por perguntas do tipo "como" ou "por quê", para situações nas quais o pesquisador tem pouco controle sobre o comportamento dos eventos e para pesquisas focalizadas em eventos contemporâneos.

A observação dessas três condições no caso em questão demonstra que essa estratégia é adequada, pois:

- o que se pretende é observar como uma forma específica de coordenação e controle ocorreu na relação interorganizacional estabelecida para implementação do programa de alfabetização de jovens e adultos na área de atuação da Sudene;

- não houve nenhum controle sobre o desenrolar dos eventos, por parte da pesquisadora;

- o caso focaliza um fenômeno contemporâneo ocorrido durante o período 1998/1999;

- segundo Yin (1994), o estudo de caso generaliza resultados para proposições teóricas e não para populações ou universos, sendo a meta do investigador expandir e generalizar teorias, ou seja, a generalização analítica. Além disso, a observação empírica dos fatos pode provocar rejeição ou reformulação de teorias, na medida em que os fatos são mais consistentes do que a teoria. Essa observação empírica pode também provocar a redefinição ou esclarecimento de teorias já existentes, uma vez que os fatos afirmam em pormenores o que a teoria afirma em termos gerais (LAKATOS,1991).

Da perspectiva da teoria contingencial, a análise de casos específicos delineados por determinadas contingências auxilia os administradores a identificar e a compreender as situações, para propor a melhor resposta para cada uma delas, pois "não existem princípios universais a serem descobertos, e cada um aprende administração experimentando um grande número de casos de situações problema" (DAFT, 1999, p.33).

O processo metodológico deste estudo de caso é baseado no método qualitativo, tendo início na construção de uma referência teórica preliminar. Prossegue pela construção de um sistema de códigos baseado no referencial teórico que servirá para a posterior classificação dos dados da pesquisa. Isso, por sua vez, facilita e confere maior qualidade à etapa de análise das evidências. Essa estrutura conceitual, previamente concebida, além de transformar a coleta de dados em um processo seletivo, dirige a pesquisa através da melhor definição do foco (MILES e HUBERMAN, 1994, p.84). 
A pesquisa se desenvolveu como um processo dinâmico em espiral, que possibilita adaptações nas várias etapas, através da reflexão iterativa entre a teoria e as evidências ao longo da pesquisa (MILES e HUBERMAN, 1994, p.85). O objetivo dessa dinâmica é uma maior qualidade nos resultados da pesquisa e de suas conseqüentes proposições.

Para consecução da análise proposta, será verificada a configuração da rede de implementadores e a gestão dessa rede quanto à coordenação do Programa de Alfabetização e Capacitação de Jovens e Adultos, cujo objetivo é diminuir o índice de analfabetismo entre jovens e adultos no Nordeste, através de cursos de curta duração em parceria com governos estaduais. Esclarecemos que a escolha do programa está vinculada a fatores de viabilidade e relevância, dentre os quais destacamos:

- execução em um curto ciclo, possibilitando a observação das diversas etapas do processo de gestão;

- apresentação de objetivos e metas quantificadas que facilitem a comparação com resultados obtidos;

- programas que sejam prioritários na agenda do governo federal, no combate às desigualdades sociais e regionais, conferindo-lhes o caráter de ação continuada;

- detalhamento dos objetivos, visando a uma melhor visualização da rede de atores envolvidos e de sua articulação.

A amostra foi do tipo não probabilística intencional (DUARTE e FURTADO,1999) e representa 40\% do universo das organizações envolvidas pelas relações interorganizacionais estabelecidas na implementação do programa. É composta de implementadores de quatro dos 10 estados abrangidos pelo programa: Alagoas, Pernambuco, Rio Grande do Norte e Ceará.

Foi em relação a esses componentes da amostra que foram realizadas as entrevistas e, ainda, a pesquisa documental dos processos formais de convênio, que envolvem: projetos, correspondências, pareceres técnicos, relatórios de acompanhamento e de prestação de contas.

Para o levantamento de dados relativos à unidade de análise, foi previamente elaborada uma estrutura de códigos relacionados aos conceitos fornecidos pela referência teórica. Esses códigos funcionam como rótulos, para indicar significados dos dados coletados durante a pesquisa, caracterizando uma teia conceitual (com definições operacionais) que inclui os significados mais importantes e suas características constitutivas (ver apêndice A).

Através da interação analítica entre os dados e a referência teórica, os códigos são revisados e podem ser alterados no decorrer da pesquisa, para melhor adequação aos propósitos desta pesquisa e ao contexto analisado (MILES e HUBERMAN, 1994).

Para possibilitar a coleta de dados em função da estrutura de códigos relacionados aos conceitos da referência teórica, foram identificados indicadores desses conceitos (ver apêndice A). Estes indicadores permitiram identificar, dentre os dados coletados, aqueles relacionados ao tema da pesquisa e lhe atribuíram significado dentro do contexto pesquisado.

Em relação às evidências, YIN (1994) considera primordial a diversificação das fontes, o estabelecimento de uma base de dados que reúna formalmente as evidências, bem como, o desenvolvimento de uma cadeia de evidências que possa explicitar as ligações entre as questões da pesquisa, os dados coletados e as conclusões elaboradas. Neste caso, como fontes de evidência foram utilizados a pesquisa documental e entrevistas individuais.

As entrevistas foram dirigidas aos ocupantes de posições gerenciais das organizações envolvidas, os quais foram responsáveis pela implementação do programa. Essa delimitação dos entrevistados se fundamenta na estreita relação entre as atividades de coordenação e controle e as funções gerenciais.

$\mathrm{Na}$ análise dos dados foi utilizado o processo de triangulação dos dados coletados por métodos distintos; no caso, pesquisa documental e entrevistas. O objetivo desse processo é a corroboração das conclusões através da 
comparação das evidências fornecidas pelas diferentes fontes de coleta de dados. Trata-se então de construir a confiabilidade da pesquisa e de suas conclusões (MILES e HUBERMAN, 1994, p.267.)

\section{Resultados e discussão}

\section{0 estabelecimento formal da rede de implementadores}

Para consecução de sua finalidade, o governo federal divide toda a ação governamental em várias funções denominadas "funções de governo", como saúde, educação e segurança. Para a elaboração do Orçamento Geral da União, cada uma das funções é dividida em programas de governo, tais como: Programa Saúde da Família, Programa Nacional de Meio Ambiente etc.

Por sua vez, os programas de governo definem as ações que serão desenvolvidas para que sejam atingidas as finalidades desses programas.

Para desenvolver essas ações, o governo federal pode descentralizar recursos para os entes federativos, ou seja, estados e municípios. Contudo, tal descentralização somente pode ocorrer após o estabelecimento de uma relação formal entre o governo federal e as entidades responsáveis pelo desenvolvimento das referidas ações.

Ao descentralizar a aplicação de recursos e execução de suas ações, o governo federal fixa uma rede de implementadores, tendo os entes federativos e órgãos de suas estruturas como executores dos programas. A justificativa para a necessidade do estabelecimento de uma rede de implementadores para a realização dos programas governamentais pode ser observada através da seguinte afirmação:

"O problema é que praticamente já não existe organização pública que consiga gerir e controlar diretamente os programas pelos quais é responsável. São tão extensas as superposições e as interdependências de políticas e programas públicos, que a base de uma administração eficaz passou a ser a coordenação de unidades que, eventualmente, visem a objetivos totalmente divergentes. Essas unidades podem ser agências do próprio Estado ou organizações privadas sem fins lucrativos que trabalham como parceiras do Estado. Isoladamente, portanto, nenhuma das estruturas organizacionais existentes consegue resolver grandes problemas ." (PEREIRA e SPINK, 1998, p.86-87).

As relações necessárias à realização das ações previstas nos programas públicos federais exigem uma formalização através de convênio, que é um instrumento assemelhado a um contrato. Por meio do convênio, o órgão da administração pública direta se compromete a repassar um determinado valor à entidade implementadora, a qual se compromete a executar o objeto pactuado, de acordo com as obrigações estipuladas no convênio. Os recursos somente serão efetivamente repassados depois de formalizado o convênio. Dessa forma, a rede de implementadores se materializa pela formalização do acordo firmado através do convênio e pela transferência de recursos.

Os partícipes de um convênio são definidos da seguinte forma (BRASIL, 1997), conforme a figura 2:

- concedente - órgão ou entidade da administração federal, responsável pela transferência de recursos destinados à execução de convênio;

- convenente ou beneficiário - entidade com a qual a administração federal pactua a execução de programa;

- interveniente - entidade que participa do convênio para manifestar consentimento ou assumir obrigações em nome próprio;

- executor - entidade diretamente responsável pela execução do objeto do convênio. 


\section{Figura 2}

Relações entre os partícipes de um dado convênio

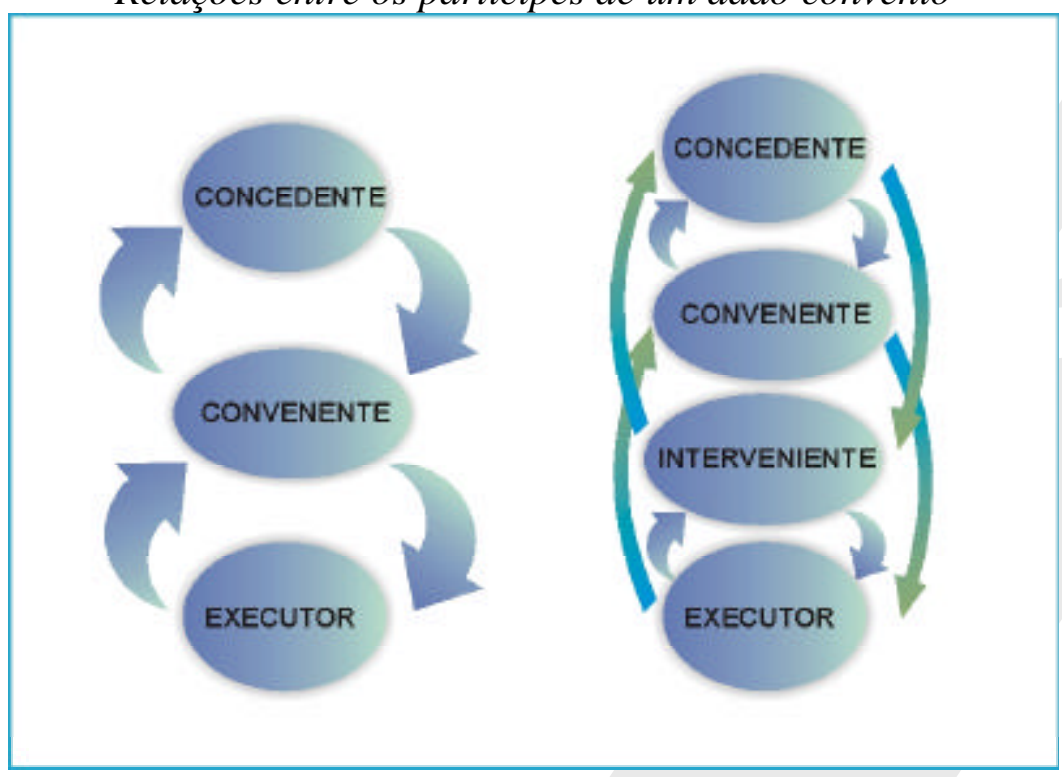

Fonte: pesquisa documental da autora.

Do ponto de vista formal, a rede se apresenta como um conjunto de organizações convenentes que mantém relações diretas com o órgão focal que é o concedente, repassador de recursos e responsável pelo controle e coordenação. Eventualmente, o convênio pode estabelecer uma figura intermediária entre o convenente e o executor denominada interveniente. Nota-se que em ambas as situações, formalmente, o executor não tem um relacionamento direto com o órgão concedente, apenas participa da rede através de conexão com o convenente ou com o interveniente. As organizações convenentes não necessariamente relacionam-se entre si, sendo a mesma afirmação válida para o caso dos executores. Tampouco as eventuais organizações intervenientes necessariamente relacionam-se entre si, embora, tanto as convenentes quanto as intervenientes se relacionem com o órgão concedente.

No estudo de caso em questão - o Programa de Alfabetização e Capacitação de Jovens e Adultos - a rede formal é estabelecida entre um órgão focal, a Sudene, como concedente, e os governos estaduais de sua área de atuação, de forma individualizada, como convenentes. Já os intervenientes constam como órgãos da própria estrutura do governo estadual, ou seja, as secretarias estaduais, sendo em três casos, repetidos como executores do programa (ver quadro 1). Essas secretarias, por sua vez, utilizam uma determinado órgão de suas estruturas internas especificamente para a execução do programa. Essas particularidades desenham uma configuração mais complexa das relações estabelecidas pela rede analisada, o que será detalhadamente descrito na próxima seção. 


\section{Quadro 1}

Identificação dos partícipes dos convênios do

Programa de Alfabetização e Capacitação de Jovens e Adultos de 1998

\begin{tabular}{|c|c|c|c|c|}
\hline CONCEDENTE & & SUDENE & & 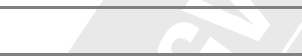 \\
\hline Convenente & $\begin{array}{l}\text { Governo de } \\
\text { Alagoas }\end{array}$ & $\begin{array}{l}\text { Governo de } \\
\text { Pernambuco }\end{array}$ & $\begin{array}{l}\text { Governo do Rio } \\
\text { Grande do Norte }\end{array}$ & Governo do Ceará \\
\hline Interveniente & $\begin{array}{l}\text { Secretaria Estadual } \\
\text { de Planejamento e } \\
\text { Desenvolvimento }\end{array}$ & Não consta & $\begin{array}{l}\text { Secretaria Estadual } \\
\text { de Planejamento e } \\
\text { Finanças }\end{array}$ & $\begin{array}{l}\text { Estadual de } \\
\text { Secretaria } \\
\text { Planejamento }\end{array}$ \\
\hline Executor & $\begin{array}{l}\text { Secretaria Estadual } \\
\text { de Planejamento e } \\
\text { Desenvolvimento }\end{array}$ & $\begin{array}{l}\text { Secretaria de } \\
\text { Estado de } \\
\text { Agricultura }\end{array}$ & $\begin{array}{l}\text { Secretaria Estadual } \\
\text { de Agricultura e } \\
\text { Abastecimento }\end{array}$ & $\begin{array}{l}\text { Secretaria Estadual } \\
\text { do Trabalho e } \\
\text { Ação Social }\end{array}$ \\
\hline
\end{tabular}

Fonte: pesquisa documental da autora.

Como já foi mencionando, vale ressaltar que existe outro nível na composição da rede de implementadores, que diz respeito à execução no âmbito local, o qual não é destacado nos termos de convênio e não está incluso nesse estudo. Dessa forma, as referências feitas aos implementadores ou executores são equivalentes e indicam o nível estadual da implementação.

De acordo com entrevistas preparatórias realizadas com os responsáveis pela coordenação de outros programas, observa-se que de modo geral os recursos para execução de tais programas são liberados próximo ao final do ano e, desse modo, a formalização dos mesmos acontece numa situação emergencial, para garantir a vinculação e a disponibilidade dos recursos financeiros. Conseqüientemente, os prazos de implementação desses programas são muito curtos e invariavelmente exigem prorrogações para sua execução. Nesse contexto, a gestão desses programas adquire um caráter contingencial, ou seja, são implementados sem um concreto planejamento anterior da ação e não incorporam estratégias significativas para a efetividade da ação. No caso analisado, por exemplo, não foi possível estabelecer precisamente a cronologia da implementação, devido à inconsistência dos dados observada na comparação de diversos documentos. Possivelmente, as atividades teriam se desenvolvido, de forma variada, durante o período de julho de 1998 a abril de 1999.

Portanto, a formalização do arranjo interorganizacional e o estabelecimento de mecanismos formais de controle delinearam todo um processo burocrático para acompanhamento da implementação do programa analisado.

\section{Formação e operação da rede de implementadores do programa analisado}

Para o delineamento do arranjo interorganizacional do programa em questão, antes de tudo, serão abordados aspectos da formação e do modo de operação da rede de implementadores. Para a concretização da referida rede, foram desenvolvidas relações interorganizacionais formalizadas por convênios entre a Sudene, como convenente - representada pela Diretoria de Programas Sociais - Divisão de Educação e Capacitação Tecnológica -, e governos estaduais. Como intervenientes e executores, ao mesmo tempo, constam as secretarias de vários governos estaduais representados nos estados pesquisados pelas secretarias de Planejamento, em Alagoas, de Ação Social, no Ceará, de Agricultura, no Rio Grande do Norte; constando apenas como executor a Secretaria Estadual de Produção Rural e Reforma Agrária, em Pernambuco (ver figura $3)$.

É necessário destacar que no âmbito das secretarias estaduais, órgãos específicos de sua estrutura são diretamente responsabilizados pela execução do programa no estado, não sendo observado um canal de contato rotineiro entre esses órgãos e o concedente.

As relações anteriormente mencionadas, além de formalizadas por convênios, foram baseadas em transações de recursos financeiros, serviços técnicos e informações. Foram repassados recursos específicos para o desenvolvimento de ações para alfabetização e capacitação de jovens e adultos, envolvendo a prestação de 
serviço técnico de alfabetização, com troca de informações em diversos momentos. Contudo, tais relações foram completamente focalizadas na Sudene como agência central, não havendo evidências de ligações entre as diversas instituições parceiras, envolvidas na execução do programa nos estados (ver figura 3). O único ponto de interação entre os executores mencionado pelos entrevistados refere-se a uma reunião que aconteceu no final do programa, para apresentação dos resultados obtidos em cada estado.

\section{Figura 3}

Configuração da rede de implementadores do Programa de Alfabetização e Capacitação de Jovens e Adultos

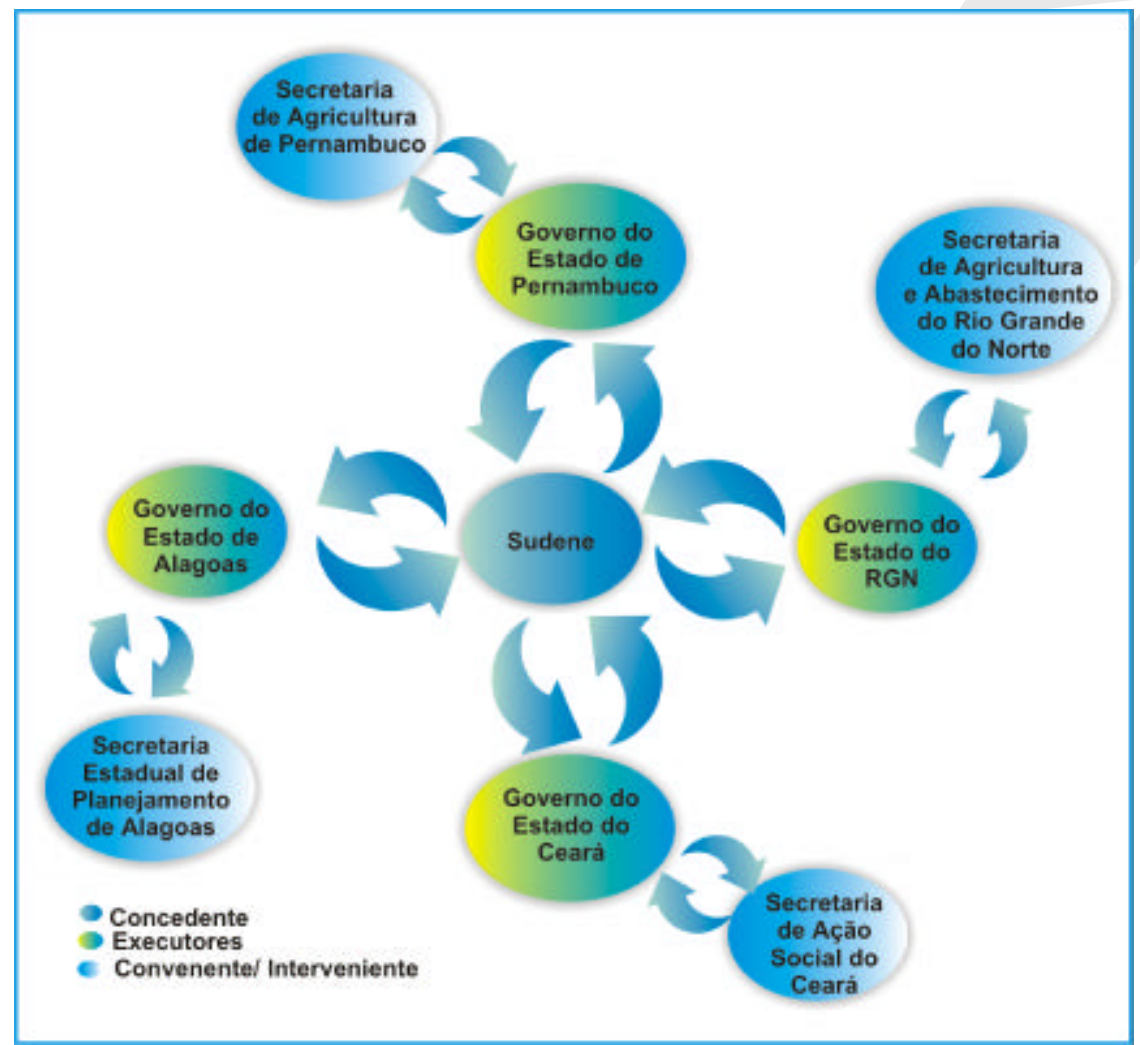

Fonte: pesquisa documental da autora.

Para Van De Ven e Walker (1979), esse padrão de arranjo é considerado um conjunto interorganizacional, no qual a organização focal mantém ligações com as organizações membros, sem que estas tenham ligações entre si. Na concepção de GRANDORI (1997), esse mesmo arranjo é denominado constelação. Esse tipo de arranjo é caracterizado sobretudo pela baixa interação entre as organizações membros, comum em arranjos mais centralizados e verticalizados, com pouca utilização de mecanismos que propiciem maior interação para troca de informações e experiências, visando incrementar o desempenho da rede como todo.

Apesar de ter sido observada uma certa autonomia na flexibilidade das formas de operacionalização dos diferenciados projetos apresentados por cada estado, a troca de experiências para otimização do desempenho da rede não aconteceu de forma significativa.

A possibilidade de execução do convênio com instituições cujos objetivos e finalidades são diferentes, ainda que façam parte da estrutura do governo estadual, denota a existência de flexibilidade na definição do executor. Nesse caso, o ponto central é sua capacidade de executar as ações que compõem o programa e dessa forma contribuir para o alcance dos objetivos deste. Nessas primeiras constatações sobre a autonomia e a flexibilidade, verifica-se o dinamismo da rede. 
Paradoxalmente, na análise desse caso, os indicadores sugeridos para definir redes dinâmicas e redes estáveis (MILES e SNOW, 1994) são mesclados em uma única situação (ver quadro 2).

\section{Quadro 2}

Características das redes quanto a sua duração, autonomia e abrangência

\begin{tabular}{|c|c|c|c|}
\hline Redes estáveis & Redes dinâmicas & Redes internas & Rede do programa \\
\hline $\begin{array}{l}\text { Coordenação da relação } \\
\text { interorganizacional } \\
\text { especializada e central. }\end{array}$ & $\begin{array}{l}\text { Relações sob } \\
\text { coordenação central, } \\
\text { onde existe uma } \\
\text { combinação da } \\
\text { avaliação central com } \\
\text { uma autonomia local. }\end{array}$ & $\begin{array}{l}\text { Relações que } \\
\text { estabelecem um } \\
\text { mercado interno de troca } \\
\text { de bens e serviços entre } \\
\text { organizações que } \\
\text { compõem uma } \\
\text { organização central. }\end{array}$ & $\begin{array}{l}\text { Coordenação da relação } \\
\text { interorganizacional } \\
\text { especializada e central } \\
\text { com combinação da } \\
\text { avaliação central com } \\
\text { uma autonomia local. }\end{array}$ \\
\hline $\begin{array}{l}\text { Relações sem prazos } \\
\text { predefinidos. }\end{array}$ & $\begin{array}{l}\text { Alianças temporárias, } \\
\text { relações com prazos } \\
\text { predefinidos. }\end{array}$ & & $\begin{array}{l}\text { Relações com prazos } \\
\text { predefinidos. }\end{array}$ \\
\hline $\begin{array}{l}\text { Relações sem prazos } \\
\text { predefinidos entre } \\
\text { organizações } \\
\text { responsáveis por etapas } \\
\text { definidas da produção de } \\
\text { bens e serviços, com } \\
\text { integração vertical. }\end{array}$ & $\begin{array}{l}\text { Entre organizações } \\
\text { responsáveis pela } \\
\text { produção de bens, com } \\
\text { integração horizontal. }\end{array}$ & & $\begin{array}{l}\text { Relações entre } \\
\text { organizações que } \\
\text { compõem uma } \\
\text { organização central, } \\
\text { responsáveis por etapas } \\
\text { definidas da produção de } \\
\text { bens e serviços, com } \\
\text { integração vertical. }\end{array}$ \\
\hline & & $\begin{array}{l}\text { Utilização dos recursos } \\
\text { humanos e materiais de } \\
\text { outras estruturas da } \\
\text { organização. }\end{array}$ & $\begin{array}{l}\text { Utilização dos recursos } \\
\text { humanos e materiais de } \\
\text { outras estruturas da } \\
\text { organização (nesse caso, } \\
\text { especificamente nas } \\
\text { atividades de } \\
\text { controle/coordenação). }\end{array}$ \\
\hline
\end{tabular}

Fonte: adaptado de Miles e Snow (1994).

Ao definir a rede dinâmica, os referidos autores mencionam as características de autonomia local, relações com prazos predefinidos e integração horizontal. Duas dessas características estão presentes na implementação do programa em questão, pois os convenentes gozaram de autonomia para se apresentarem como o próprio executor, utilizando para isso órgãos da sua estrutura interna. O convenente pôde ainda propor seu plano de trabalho com estruturas e metas diferenciadas, conforme observado nos projetos apresentados por cada estado e no plano de trabalho específico que compõe cada um dos termos de convênio. ${ }^{1}$

O caráter temporário dessa aliança - cujo prazo de vigência é determinado conforme verificado nos cronogramas de implantação especificados no convênio - também se apresenta como uma característica das redes dinâmicas. Apesar das possibilidades de prorrogações, o próprio termo de convênio estabelece uma data limite para o total encerramento do programa, que também pode ser considerado como prazo para a desarticulação do arranjo interorganizacional usado para a implementação.

A forma de articulação das organizações evidencia a verticalização na cadeia de produção dos serviços (ver quadro 3); ou seja, o convênio define a Sudene como órgão do governo federal responsável pela coordenação

\footnotetext{
${ }^{1} 0$ convênio é um instrumento semelhante a um contrato, no qual o órgão da administração pública direta se compromete a repassar um determinado valor e 0 ente beneficiário se compromete a executar 0 objeto pactuado, de acordo com as obrigações estipuladas no convênio.
} 
geral do programa em um nível estratégico. Este órgão se articula com os governos estaduais para montar uma estrutura com capilaridade suficiente para fazer os recursos e benefícios do programa chegarem ao nível local em um nível tático. Por sua vez, os executores integrantes da estrutura de governo estadual que cuidam do nível operacional articulam com a esfera municipal, para garantir exeqüibilidade ao programa, por meio de estruturas físicas e recursos humanos locais. Nesse modo de operação, as diferentes organizações são responsáveis por etapas distintas da produção de serviços, demonstrando integração vertical. Esse relacionamento em cadeia vertical de produção é uma característica da rede estável (MILES e SNOW, 1994).

Quadro 3

Papéis/descentralização observados no

Programa de Alfabetização e Capacitação de Jovens e Adultos

\begin{tabular}{|c|c|c|c|c|}
\hline DECISÕES/ATIVIDADES & 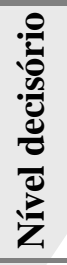 & $\frac{\tilde{\Xi}}{\tilde{E}}$ & 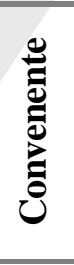 & 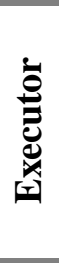 \\
\hline Define a missão e as estratégias do programa. & E & $\mathrm{x}$ & & \\
\hline Define a metodologia de trabalho a ser adotada. & E & $\mathrm{x}$ & & $\mathrm{x}$ \\
\hline Avalia o andamento do programa. & E & $\mathrm{x}$ & & \\
\hline stabelece objetivos e metas para o programa. & $\mathrm{E}$ & $\mathrm{x}$ & & \\
\hline Aprova planos de trabalho. & E & $\mathrm{x}$ & & \\
\hline Aprova a prestação de contas. & E & $\mathrm{x}$ & & \\
\hline Decide sobre a manutenção, incorporação ou desativação do programa. & E & $\mathrm{x}$ & & \\
\hline $\begin{array}{l}\text { Acompanha e avalia o programa, alterando prazos, realocando recursos, } \\
\text { redefinindo metas e objetivos. }\end{array}$ & $\mathrm{T}$ & $\mathrm{x}$ & $\mathrm{x}$ & \\
\hline Estabelece normas e procedimentos em seu campo de ação. & $\mathrm{T}$ & $\mathrm{x}$ & $\mathrm{x}$ & \\
\hline $\begin{array}{l}\text { Tem iniciativa para modificar rotinas e procedimentos técnicos e } \\
\text { administrativos. }\end{array}$ & $\mathrm{T}$ & $\mathrm{x}$ & & $\mathrm{X}$ \\
\hline Propõe eventos. & $\mathrm{T}$ & $\mathrm{x}$ & & $\mathrm{x}$ \\
\hline $\begin{array}{l}\text { Tem iniciativa para propor adaptações e modificações nos objetivos, nas } \\
\text { metas, nas atividades e nas tarefas a serem desenvolvidas. }\end{array}$ & $\mathrm{O}$ & & $\mathrm{x}$ & $\mathrm{x}$ \\
\hline Distribui tarefas a serem desempenhadas pelos técnicos. & $\mathrm{O}$ & & & $\mathrm{x}$ \\
\hline Avalia os resultados obtidos pelo programa. & $\mathrm{O}$ & $\mathrm{x}$ & & $\mathrm{x}$ \\
\hline $\begin{array}{l}\text { Decide sobre a participação em eventos locais, que não impliquem em } \\
\text { gastos , no âmbito do programa. }\end{array}$ & $\mathrm{O}$ & & & $\mathrm{x}$ \\
\hline
\end{tabular}

Legenda: E- estratégico; T- tático; O- operacional; X- responsável pela decisão/ação.

Fonte: adaptado de Tenório (2000, p.74-75).

Ainda analisando as relações de rede presentes nesse caso, sob a ótica de Miles e Snow (1994), também ficam evidentes as características da rede interna, pois ocorre a utilização de recursos humanos e materiais de outras estruturas da organização não ligados diretamente ao programa. Isso pode ser observado tanto da parte da organização focal (Sudene), quanto da parte dos governos estaduais que compõem a rede. A Sudene, especificamente nas atividades de controle, utilizou seus escritórios regionais para realizar visitas de acompanhamento, enquanto os governos estaduais utilizaram recursos humanos e materiais de instituições que fazem parte da estrutura do governo estadual, como contrapartida de aplicação de recursos. Foi, por exemplo, o caso da participação da Emater, que no Rio Grande Norte coordenou todo o programa e em Pernambuco participou do desenvolvimento de cursos de capacitação.

O aproveitamento do potencial dos escritórios regionais da Sudene foi pouco mencionado nas entrevistas; e em alguns estados os entrevistados informaram que não tiveram contato com as representações estaduais do órgão. Apesar disso, na pesquisa documental, foram encontradas evidências de que esses escritórios participaram do 
acompanhamento do programa em sua fase inicial. Existem diversos relatórios elaborados por técnicos dos escritórios regionais de representação estadual da Sudene, dando conta da evolução da implementação do programa em cada estado.

Ainda analisando as características da estrutura interorganizacional do programa, podemos compará-las com a tipologia de Grandori e Soda (1995) (ver quadro 4). Essa tipologia focaliza o grau de formalização e de descentralização no relacionamento interorganizacional. O relacionamento constatado no programa se aproxima daquele que os referidos autores chamam de redes burocráticas, formalizadas por meio de acordos ou contratos de troca ou associação. No caso em estudo, o relacionamento está formalizado por meio do termo de convênio que estipula os direitos e obrigações das partes envolvidas.

Quanto às características próprias das redes sociais e redes proprietárias descritas por Grandori e Soda, não foram observadas no caso em questão, pois as relações estabelecidas não são essencialmente sociais, embora estejam presentes em qualquer rede. Da mesma maneira, não houve evidências de sistemas de incentivo à cooperação baseados na partilha dos direitos de propriedade. ${ }^{2}$ Ademais, não há evidências de um sistema de informações que pudesse ser utilizado de forma partilhada, como será discutido mais adiante.

\section{Quadro 4}

\section{Características das redes quanto ao grau de formalização}

\begin{tabular}{ll} 
Redes sociais & $\begin{array}{l}\text { Redes não formalizadas, dedicadas apenas à troca de bens sociais } \\
\text { Existência de relações de troca de informações e ausência de acordos } \\
\text { ou contratos formais. }\end{array}$ \\
\hline Redes burocráticas & $\begin{array}{l}\text { Redes formalizadas por acordos ou contratos de troca ou associação. } \\
\text { Existência de relações com acordos ou contratos formais }\end{array}$ \\
\hline Redes proprietárias & $\begin{array}{l}\text { Redes formalizadas que utilizam o direito de propriedade como } \\
\text { sistema de incentivo à cooperação. Sistemas de incentivo baseados na } \\
\text { partilha dos direitos de propriedade. }\end{array}$ \\
\hline Rede do programa analisado & $\begin{array}{l}\text { Rede formalizada por convênios que definem relações de troca de } \\
\text { recursos e execução de serviços, sem a utilização do direito de } \\
\text { propriedade como incentivo à cooperação. }\end{array}$ \\
\hline
\end{tabular}

Fonte: adaptado de Grandori e Soda (1995).

\section{Conclusão}

A rede montada para a implementação do Programa de Alfabetização e Capacitação de Jovens e Adultos de 1998 assumiu a configuração de conjunto interorganizacional (VAN DE VEN e WALKER, 1979) ou constelação (GRANDORI, 1997), caracterizado por relações formais, de pares, entre a agência central e os demais implementadores, as quais estiveram baseadas na transação de recursos financeiros e serviços técnicos. A celebração de convênios para o estabelecimento da rede confere às relações interorganizacionais um caráter formal, caracterizando o arranjo como uma rede predominantemente burocrática.

A ausência de comunicação e de troca de informações entre os implementadores indica uma forte centralização com atividades verticalizadas, pois não houve qualquer indício de interdependência entre as demais organizações.

Apesar de ter características de uma rede dinâmica, no que diz respeito ao caráter temporário das relações, e de uma certa autonomia local, há um forte controle burocrático central, com atividades verticalizadas, o que pode sugerir uma incoerência na configuração observada. Isso quer dizer que existe presença simultânea de características das redes dinâmicas e das redes estáveis num mesmo arranjo interorganizacional.

\footnotetext{
${ }^{2}$ Segundo os entrevistados, não houve sistematização de informações que tivessem valor transacional, ou dados que fossem úteis a outras aplicações, como dados estatísticos para planejamento.
} 
Quanto ao aproveitamento da rede interna da agência central, no caso a Sudene, o que chama a atenção é a subutilização da estrutura disponível, considerando sua capilaridade, apesar da relatada escassez de recursos financeiros.

A configuração do arranjo interorganizacional segue, então, um padrão altamente formalizado, sujeito a fortes restrições devido à contingência de escassez de tempo e de recursos, não refletindo uma constituição resultante de um planejamento consolidado.

As proposições que se seguem foram apresentadas de forma agregada, uma vez que os aspectos analisados, no caso pesquisado, são considerados estreitamente relacionados entre si.

Antes de tudo, merece especial atenção a presença simultânea de características de redes dinâmicas e de redes estáveis, sugerindo uma incoerência na configuração do arranjo interorganizacional; sendo que alternativas a essa incoerência poderiam ser apresentadas em dois sentidos. Se de um lado, o que se pretende é o estabelecimento de uma ação contínua, para alcançar o objetivo específico de alfabetização de jovens e adultos, uma rede fixa com relações sem prazo determinado pode ser proposta com papéis bem definidos em escala vertical. Isso significa que a definição das funções dos órgãos nos âmbitos federal e estadual - inclusive, no âmbito municipal ou no local -, não são atualmente definidos dentro do programa, que faz referência apenas às obrigações da agência central e dos governos estaduais. ${ }^{3}$

Por outro lado, se o que se pretende é o desenvolvimento de ações incrementais ${ }^{4}$ em contextos específicos que aliás também é uma característica deste programa, já que foi desenvolvido dentro de um programa maior, cujo objetivo é contextualizado na crise do período da seca -, é possível propor uma integração horizontal para maximizar os resultados em períodos mais curtos, somando o maior número de competências específicas disponíveis. Dessa forma, a rede poderia ser estabelecida entre organizações cuja competência está relacionada ao objetivo do programa, e não necessariamente entre organizações do setor público estatal.

Em ambas as alternativas as relações poderiam ser mais flexíveis, seguindo a nova tendência na perspectiva da administração pública gerencial focalizada em resultados que propiciem a efetividade das ações de governo, em vez do controle centrado nos gastos governamentais. Na linha desse argumento, Pereira e Spink (1998) observam que:

"Na atual era de escassez de recursos por que passa o Estado, duas lógicas antagônicas aparecem como alternativas. Uma é a fiscal, preocupada em controlar os inputs do sistema, para evitar o aumento dos custos. Outra é a gerencial, que busca aumentar a eficiência e a efetividade, de tal forma que sua lógica se baseia em atingir os objetivos, ou seja, obter melhores outputs. Nesse embate, enquanto a primeira lógica praticamente só se preocupa com o quanto se gasta nos serviços públicos, atuando apenas no curto prazo, a segunda pretende tornar mais produtiva a ação da burocracia...".

A característica de centralização observada no programa, por sua vez, conduz à idéia de subaproveitamento da rede interna da Sudene. Nesse sentido, poderia ser proposta uma coordenação e controle regional da implementação, através de um planejamento envolvendo as representações regionais da agência central, com melhor distribuição das atividades de coordenação e controle entre as mesmas, permanecendo a cargo da unidade central Sudene, neste caso a Diretoria de Programas Sociais, através de sua divisão responsável, a articulação, negociação e definição de estratégias gerais, funcionando como uma unidade organizacional de coordenação.

Enfim, tais considerações sobre o arranjo interorganizacional em questão visam, sobretudo, contribuir para uma maior eficiência no desenvolvimento das ações governamentais.

\footnotetext{
${ }^{3} 0$ plano de trabalho e o termo de convênio que formalizam a relação somente fazem referência às responsabilidades da agência central e dos órgãos estaduais. 0 próprio programa não prevê as funções dos atores do âmbito local.

${ }^{4}$ Diz respeito ao desenvolvimento de ações complementares, como, por exemplo, alfabetização seguida da capacitação e da alocação de mão- deobra.
} 


\section{Referências bibliográficas}

ALEXANDER, E. R. A structuration theory of inteorganizational coordination: cases in environmental management. International Journal of Organizational Analysis, v.6, p.334-354, Oct.1998.

BRASIL. Instrução Normativa da Secretaria do Tesouro Nacional, de 01/97. Disciplina a celebração de convênios de natureza financeira, que tenham por objetivo a execução de projetos ou a realização de eventos, e dá outras providências. Diário Oficial da República Federativa do Brasil, Braślia, DF, 31 jan.1997.

DAFT, R. L. Administração. Rio de Janeiro: LTC, 1999.

DUARTE , Simone V. e FURTADO, Maria Sueli. Manual para elaboração de monografias e projetos de pesquisa. Montes Claros: UNIMONTES, 1999.

GRANDORI, A. An organizational assessment of inter-firm coordination modes. Organization Studies, v.18, n.6, p.897-925, 1997. ; SODA, G. Inter-firm networks: antecedents, mechanisms and forms. Organization Studies, v.16, n.2, p183-214, 1995.

GRAU, N. C. Repensando o público através da sociedade: novas formas de gestão pública e representação social. Rio de Janeiro: Revan; Brasília, DF: Enap, 1998.

HALL, R. H. Organizations: structures, processes and outcomes. 6.ed. New J ersey: Prentice Hall, 1996.

JENNINGS JR, E. T. Interorganizational coordination, administrative consolidation, and policy performance. Public Administrative Review, Washington, v.58. p.417-428, Sept./Oct. 1998. (Base de dados Proquest).

KALUZNY, A. D. Inteorganizational factors affecting the delivery of primary care to older Americans. Health Services Research, Chicago, v.33, p.381-401, June 1998. (Base de dados Proquest).

KLINE, K. D. Defining the implementation problem: organizational management versus cooperation. Journal of Public Administration Research and Theory, v.10, p.551-571, 2000.

LAKATOS, E. M. Metodologia científica. 2.ed. São Paulo: Atlas, 1991. p.39.

LEVINE, S.; WHITE, P. E. Exchange as conceptual framework for the study of interorganizational relationships. Administrative Science Quarterly, v.5, p.583-601, 1961.

LITWALK, E.; HYLTON L. F. Interorganizational analysis: a hypothesis on coordinating agencies. Administrative Science Quarterly, v. 6 , p.395-420, 1962

MARRET, C. B. On the specification of interorganizational dimensions. Sociology and Social Research. v.56, p.83-99, 1971.

MILES, M. B.; HUBERM AN, A M. Qualitative data analysis: an expanded sourcebook. 2.ed. Thousand Oaks, CA: Sage Publications, 1994.

MILES, R. E.; SNOW, C. C. F. Fit, failure and the hall of fame. New York. Free Press, 1994.

UNIVERSIDADE ESTADUAL DE CAM PINAS - UNICAMP, Núcleo de Estudos de Políticas Públicas - NEPP. 0 processo de implementação de políticas públicas no Brasil: características e determinantes da avaliação de programas e projetos. Cadernos de pesquisa n.48, Campinas/SP: UNICAMP, 2000.

OLIVER, C. Determinants of interorganizational relationships: integration and future directions. Academy of Management Review , v.15. p.241-265, 1990.

PEREIRA, L. C. B. A reforma do estado dos anos 90: lógica e mecanismos de controle - Cadernos Mare, Brasília-DF, n.1, 1997. ; GRAU, N. C. 0 público não estatal na reforma do Estado. Rio de Janeiro: Editora FGV, 1999.

; SPINK, P. K. (Orgs.). Reforma do Estado e administração pública gerencial.2.ed. Rio de Janeiro: Editora FGV, 1998.

PRESSMAN, J. L.; WILDAVSKY, A. B. Implementation. California: Berkley University of California Press, 1974.

SALANCIK, G. R. Wanted: a good network theory of organization. Administrative Science Quarterly, v. 40, p.345-349, 1995.

TENÓRIO, F. (Org.). Gestão de ONGs - principais funções gerenciais. Rio de Janeiro: Editora Fundação Getúlio Vargas, p.74- 75, 2000.

VAN DE VEN, A. H.; WALKER, G. Coordination patterns within an interorganizational network. Human Relations, v. 32, n.1, p.19- 36, 1979.

YIN, R. K. Case study research: design and methods. 2.ed. Thousand Oaks: Sage Publications, 1994. p.22. 


\section{Apêndice A}

Indicadores de estruturas de coordenação

\begin{tabular}{|c|c|c|c|}
\hline CÓDIGO & ITEM & DEFINIÇÃO & INDICADORES \\
\hline CRD. & $\begin{array}{l}\text { Coordenação } \\
\text { interorganizacional }\end{array}$ & $\begin{array}{l}\text { Identificação e gerenciamento da } \\
\text { interdependência de um arranjo de } \\
\text { organizações, através de } \\
\text { estruturas de coordenação } \\
\text { interorganizacional, para ajustar } \\
\text { suas respectivas ações. Essas } \\
\text { estruturas são definidas em três } \\
\text { diferentes níveis. }\end{array}$ & $\begin{array}{l}\text { Relações baseadas em linhas de } \\
\text { comando, em trocas relacionadas a } \\
\text { preços, em confiança - formato } \\
\text { dado pela formalização das } \\
\text { relações - e, finalmente, } \\
\text { mecanismos operacionais de } \\
\text { coordenação, como comunicação, } \\
\text { decisão, informação, planejamento, } \\
\text { assessoria e sistemas de incentivo. }\end{array}$ \\
\hline CRD.HIQ & $\begin{array}{l}\text { Metaestrutura } \\
\text { hierárquica }\end{array}$ & $\begin{array}{l}\text { Explicitada por ligações baseadas } \\
\text { no comando por autoridade. }\end{array}$ & $\begin{array}{l}\text { Formalização de comunicações } \\
\text { conforme as ligações hierárquicas, } \\
\text { contratos ou convênios que } \\
\text { regulem as relações entre as } \\
\text { organizações. }\end{array}$ \\
\hline CRD.MER & $\begin{array}{l}\text { Metaestrutura de } \\
\text { mercado }\end{array}$ & $\begin{array}{l}\text { Explicitada por relações de troca } \\
\text { relacionadas a preço; } \\
\text { caracterizadas pelo ajustamento } \\
\text { mútuo espontâneo. }\end{array}$ & $\begin{array}{l}\text { Contratos de negociação de bens e } \\
\text { serviços baseados em preços. }\end{array}$ \\
\hline CRD.SOL & $\begin{array}{l}\text { Metaestrutura de } \\
\text { associação solidária }\end{array}$ & $\begin{array}{l}\text { Ligações baseadas na confiança } \\
\text { caracterizada pela utilização de } \\
\text { valores compartilhados. }\end{array}$ & $\begin{array}{l}\text { Ausência ou baixo grau de } \\
\text { controle. }\end{array}$ \\
\hline CRD.MSO & Mesoestruturas & $\begin{array}{l}\text { Referem-se à forma e abrangem } \\
\text { um sistema particular de arranjo } \\
\text { interorganizacional, estando } \\
\text { relacionados ao nível da } \\
\text { implementação. }\end{array}$ & $\begin{array}{l}\text { Formato adquirido pela } \\
\text { formalização das relações. Tais } \\
\text { como alianças, joint ventures, } \\
\text { associação/federação, programas e } \\
\text { projetos. }\end{array}$ \\
\hline
\end{tabular}


Indicadores de mecanismos de coordenação

\begin{tabular}{|c|c|c|c|}
\hline CÓDIGO & ITEM & DEFINIÇÃO & INDICADORES \\
\hline MEC.COM & $\begin{array}{l}\text { Mecanismos de } \\
\text { comunicação }\end{array}$ & $\begin{array}{l}\text { Canais de comunicação formal } \\
\text { ou informal. }\end{array}$ & $\begin{array}{l}\text { Memorando, fax, circulares, contatos } \\
\text { telefônicos e correspondência } \\
\text { eletrônica. }\end{array}$ \\
\hline MEC.DEN & $\begin{array}{l}\text { Mecanismos de } \\
\text { decisão e } \\
\text { negociação }\end{array}$ & $\begin{array}{l}\text { Canais, mecanismos e } \\
\text { estruturas para tomada de } \\
\text { decisão e negociação. }\end{array}$ & $\begin{array}{l}\text { Reunião de representantes, conselhos } \\
\text { ad hoc e junta diretora. }\end{array}$ \\
\hline MEC.CTS & $\begin{array}{l}\text { Coordenação e } \\
\text { controle social: }\end{array}$ & $\begin{array}{l}\text { Baseada em normas, reputação } \\
\text { e controle mútuo, aplica-se às } \\
\text { relações estáveis que, por sua } \\
\text { vez, implicam um aspecto } \\
\text { social. }\end{array}$ & $\begin{array}{l}\text { Normas estabelecidas, avaliações } \\
\text { feitas pelos envolvidos e parâmetros } \\
\text { de conduta. }\end{array}$ \\
\hline MEC.UNF & $\begin{array}{l}\text { Unidades e } \\
\text { funções }\end{array}$ & $\begin{array}{l}\text { Unidades ou funções } \\
\text { responsáveis pela ligação e } \\
\text { integração. }\end{array}$ & $\begin{array}{l}\text { Formalização da figura do } \\
\text { administrador de projetos e } \\
\text { composição formal de junta diretora. }\end{array}$ \\
\hline MEC.ASE & $\begin{array}{l}\text { Assessoria } \\
\text { comum }\end{array}$ & $\begin{array}{l}\text { Corpo administrativo comum, } \\
\text { como uma estrutura de } \\
\text { coordenação central. }\end{array}$ & $\begin{array}{l}\text { Formalização de uma estrutura de } \\
\text { coordenação central composta por } \\
\text { especialistas, com definição de } \\
\text { atribuições relativas à coordenação } \\
\text { da rede. }\end{array}$ \\
\hline MEC.PLC & $\begin{array}{l}\text { Sistemas de } \\
\text { planejamento e } \\
\text { controle }\end{array}$ & $\begin{array}{l}\text { Sistemas de planejamento e } \\
\text { controle baseados em } \\
\text { resultados. }\end{array}$ & $\begin{array}{l}\text { Formalização de processos de } \\
\text { planejamento e controle baseados em } \\
\text { resultados, com metas e objetivos } \\
\text { quantificáveis. }\end{array}$ \\
\hline MEC.INC & $\begin{array}{l}\text { Sistemas de } \\
\text { incentivo }\end{array}$ & $\begin{array}{l}\text { Mecanismos de incentivo, tais } \\
\text { como o direito de propriedade } \\
\text { partilhado. }\end{array}$ & $\begin{array}{l}\text { Formalização de sistemas de } \\
\text { incentivo, verificados através da } \\
\text { formalização de benefícios adicionais } \\
\text { relacionados a metas ou objetivos. }\end{array}$ \\
\hline MEC.INF & $\begin{array}{l}\text { Sistemas de } \\
\text { informação }\end{array}$ & $\begin{array}{l}\text { Sistema de informação para } \\
\text { integração de redes extensas. }\end{array}$ & $\begin{array}{l}\text { Sistemas de informação partilhados, } \\
\text { tanto informais como formais. }\end{array}$ \\
\hline
\end{tabular}

